An extremity osteosarcoma developed in another bilateral retinoblastoma patient after 4 years.

Conclusions Since, the risk of this re-occurrence is associated with the dose of some chemotherapeutics cumulatively, the radiation field and the use of minimal therapy that has the maximum efficacy according to the diagnosis, age, stage and risk of the patient is important.

\section{AN EDUCATIONAL PROGRAMME FOCUSING ON PAEDIATRIC FRACTURE IDENTIFICATION MAINTAINS A LOW FALSE-NEGATIVE RADIOGRAPH INITIAL REPORT RATE IN EMERGENCY MEDICINE}

doi:10.1136/archdischild-2012-302724.1554

T Fox, A Rowland. Paediatric Emergency Department, North Manchester General Hospital, Pennine Acute Hospitals NHS Trust, Manchester, UK

Introduction False negative radiograph reports constitute greater than $80 \%$ of all diagnostic errors in Emergency Departments (EDs) with reported levels of false negative initial reports around 1\%.

Method The records of all patients recalled to the Emergency Department clinics for management of a possible false-negative initial radiograph report were examined $(n=46)$, following which the junior emergency medicine doctors received three tutorials on fracture identification and management. A re-audit was completed.

Results Between $1^{\text {st }}$ September 2010 and $16^{\text {th }}$ January 2010 a false negative radiograph report rate of $0.72 \%$ was identified. There were proportionally more false negatives in patients aged under 16. Between $16^{\text {th }}$ January and $31^{\text {st }}$ May 2011, after the educational intervention, the false negative radiograph report rate had dropped to $0.62 \%$. The percentage reduction in false negative reports was $13.8 \%$ $(\mathrm{p}=0.53)$.

Conclusions These results suggest that a well developed educational programme is an effective way of maintaining a low level of false negative initial reports in an Emergency Department.

False negative reports were most likely in fractures of the foot, wrist, elbow and those in the paediatric population. Educational sessions should focus on identification of these fractures. Mistakes in diagnosis can occur when an inexperienced clinician dismisses a positive clinical examination after mis-interpreting an imaging investigation. Encouraging senior review of paediatric radiographs could help to maintain a low false-negative report rate.

This study indicates that educational interventions may have the potential to improve patient care in the Emergency Department setting. Further ways to reduce human error need to be explored.

\section{A REVIEW OF SAFEGUARDING DOCUMENTATION IN PAEDIATRIC TRAUMA PATIENTS}

doi:10.1136/archdischild-2012-302724.1555

${ }^{1} \mathrm{~A}$ Mirdin, 'A Kent, ${ }^{1} \mathrm{AS}$ Lindsay, ${ }^{2} \mathrm{M}$ Vaidya, 'A Parikh. 'Paediatric Emergency Department; ${ }^{2}$ Paediatric Critical Care, Barts Health NHS Trust, London, UK

Background The Royal London Hospital is a Major Trauma Center (MTC) in East London. In 2011, we saw approximately 300 paediatric traumas. Our borough has one of the highest rates of safeguarding issues in the country. Therefore, awareness and documentation of these issues is paramount.

Aim To determine the quality of safeguarding documentation in paediatric trauma patients presenting to the Major Trauma Centre (MTC).

Methods A retrospective analysis of documentation of paediatric trauma patients notes presenting to the Emergency Department at the Royal London Hospital between 1st January 2011 and 1st January 2012. A register of patients was obtained from the Emergency Department database and trauma database. There are no current UK guidelines regarding minimum standards of safeguarding documentation in the paediatric population in the UK. We defined the audit standard as the minimum level of documentation required to satisfy Barts Health NHS trust and local policies.

Results Projected results indicate safegaurding documentation may be inadequate in greater than $90 \%$ of cases.

Conclusions Current standards of safeguarding documentation within our Major Trauma Centre will be significantly below the minimum standard required at a local level. This has implications nationally where analysis would be expected to achieve a similar outcome.

\section{A PROSPECTIVE REVIEW OF NITROUS OXIDE SEDATION POST INTRODUCTION OF A PAEDIATRIC PROCEDURAL SEDATION PROGRAMIME IN A PAEDIATRIC EMERGENCY DEPARTMENT}

doi:10.1136/archdischild-2012-302724.1556

1,2S McCoy, ${ }^{1} \mathrm{D}$ Barrett, ' $\mathrm{S}$ Walsh, ${ }^{1,2,3 \mathrm{R}}$ 0'Sullivan. 'Department of Emergency Medicine, Paediatric Emergency Research Unit (PERU), Our Lady's Children's Hospital; ${ }^{2}$ National Children's Research Centre; ${ }^{3}$ Department of Paediatrics, University College Dublin, Dublin, Ireland

Background and Aims Introduction of a structure Paediatric Procedural Sedation (PPS) Programme facilitates Emergency Department (ED) staff in the safe and efficacious practice of PPS in the ED. Methods Nitrous oxide was introduced into our institution in July 2011, as part of a PPS programme in the ED. All ED staff (doctors and nurses) must complete the sedation programme before preforming any sedation in the ED. Each sedation event is prospectively recorded on a specific paediatric emergency department sedation checklist and recorded data is then entered into a Microsoft Access ${ }^{\circledR}$ database.

Results Since the programme introduction 82 sedation events have been recorded. The majority of patients were male (49:33 M:F) with an average age of 6 years (17months - 15yrs). The indications for sedation were as follows: Joint manipulation (17), Removal of Foreign Body (12), Suturing (45) and Other (8). We have recorded a total of $17(20 \%)$ adverse events: most commonly, vomiting and agitation. The majority of procedures were performed by ED staff, however some required a specialist to perform the procedure: Plastic Surgery, General Surgery and Orthopedics. Without the provision of sedation in the ED the majority of these patients would have required hospital admission for general anaesthesia.

Conclusion The introduction of nitrous oxide as a sedative agent for procedures in children in our ED has been successful. With low adverse event rates which are comparable to international experience and no serious adverse events have been noted.

\section{IMPLEMENTATION OF A PROCEDURAL SEDATION PROGRAMME IN A TERTIARY PAEDIATRIC EMERGENCY DEPARTMENT}

doi:10.1136/archdischild-2012-302724.1557

1.2SC McCoy, 'D Barrett, 'S Walsh, 1,2,3R 0'Sullivan. 'Department of Emergency Medicine, Paediatric Emergency Research Unit (PERU), Our Lady's Children's Hospital; ${ }^{2}$ National Children's Research Centre; ${ }^{3}$ Department of Paediatrics, University College Dublin, Dublin, Ireland

Background and Aims In the conduct of Paediatric Procedural Sedation (PPS) within the Emergency Department (ED) the combination of powerful drugs, variable competency levels and high staff turnover carry the potential for sedation-associated adverse events. Yet, currently, there is no set programme for education and accreditation of Irish ED staff in PPS. We describe the introduction of a structured educational programme for PPS within the ED for all ED clinical staff. 